\title{
The Impact of Beijing Hukou on Contemporary Women's Mate Preferences, and Male Attractiveness
}

\author{
Ruoyi Fang ${ }^{1 *}$, Haoyang Zhou ${ }^{2}$, Xiyun $\mathrm{Hu}^{3}$, Chenyu Yang ${ }^{4}$ \\ ${ }^{1}$ The School of Languages, Cultures and Societies, University of Leeds, Leeds, LS2 9JT, UK \\ ${ }^{2}$ Faculty of Art and Social Sciences, Dalhousie University, B3H 4J1, Canada \\ ${ }^{3}$ Nanjing Foreign Language School British Columbia Academy, Nanjing, Jiangsu 210008, China \\ ${ }^{4}$ Tung wah senior high school, Dongguan, Guangdong, 523128, China \\ ruoyieva@gmail.com;'hy910554@dal.ca
}

\begin{abstract}
In China's marriage market, the location of a man's household registration can shape a woman's choice of spouse. Two members of this paper's group, based on their experiences on dating websites, found that contemporary Chinese women immensely prefer Beijing Hukou. There is a massive difference in how women seek a mate by changing their domicile on dating sites. According to previous studies, women of any era prefer men with more assets, occupation and social status.[1] Why, then, do contemporary Chinese women strongly prefer Chinese men to have Beijing household registration? This preference even exceeds the preference for high-asset men. What is the relationship between Beijing hukou and masculinity? Does this relationship subvert or reproduce our previous perceptions and theories? This paper will focus on why Chinese women tend to choose Beijing hukou.
\end{abstract}

Keywords: Beijing Hukou, mate preference, male attractiveness, gender, marriage market

\section{INTRODUCTION}

People's criteria for choosing a spouse have been a long-standing topic in the marriage market. Women do not have the exact requirements for their spouses or husbands in different cultural contexts and national policies.

In China, Hukou, a unique household registration system, has become one of the crucial criteria for choosing a spouse in the Chinese marriage market. Some studies have shown that women choose their mates in preference to men with more developed urban hukou. This phenomenon has a direct impact on the nationwide mobility of Chinese women. The tendency to migrate through marriage exacerbates the imbalance in development between cities and further widens the value gap between hukou in different cities. "Scholars believed that the hukou system greatly influenced people's social mobility, educational attainments, employment opportunities, and labour-market return." [2]

This article will present that Beijing hukou greatly influences Chinese women's mate selection through survey data in Chinese online dating platforms. And using[3] research articles as a theoretical basis will explain why Beijing hukou has an excellent allure for women choosing a spouse.

\section{HUKOU}

The Hukou system, implemented in the People's Republic of China, is a family-based politics of population management. Regions are divided by cities, making a distinction between rural hukou and urban hukou to control population migration. In 1951, the Chinese government promulgated New China's first population management regulations [4]. This regulation determined that only residents who owned an urban hukou or had a long-term residence permit could reside in the city permanently.

The location of the hukou is generally the birthplace of the hukou holder. Hukou relocation methods include, but are not limited to, marriage, work, and running a business. As the population of some cities gradually increases, the requirements for obtaining a hukou in this city become stringent. Take Beijing as an example. From 1984 to 2014, Beijing's legal resident population grew from 8.94 million to 21.89 million, with a 
migratory population of nearly 30 million [5].In contrast, the requirement to obtain a Beijing household registration has changed from marrying a local Beijinger to obtaining a Beijing household registration after ten years of marriage[4].

Under such a hukou system, China's population migration has been effectively controlled, but relative resource inequality has gradually arisen. The social benefits and resources available to Chinese citizens in different hukou are not the same. "The urban residents in that location (say a municipality) are favoured in resource allocation compared to the rural residents and migrants." [6]

Such inequality has gradually prompted Chinese citizens to use various methods to obtain hukou in the more developed cities. Marriage is one of the ways to obtain hukou in more developed cities.

\subsection{What we experienced?}

Two members of this paper experienced that Beijing hukou was indeed desirable for Chinese women. Several accounts were registered on some famous Chinese dating websites and dating apps. Some accounts show they are from Beijing, and their introductions say "Beijing Hukou." Other accounts were set to some relatively less developed regions. The gender of these accounts was males. Three weeks after posting the information on these accounts, an unusually high number of messages were sent to the mailbox, with over 200 women trying to talk. At the same time, hundreds of women set the "Beijing" account as "desired." Comparatively these three accounts from other cities received only a few messages, which is in stark contrast to the "Beijing" account. From this experiment, we argue that even on dating websites and dating apps, women's desire for a Beijing account has far surpassed their desire for an account from other cities. The Beijing account has become extremely popular in China's dating market. Clearly, men with Beijing hukou are at the top of the pyramid in the dating market.

\subsection{Why is the Beijing hukou so crucial in the dating market?}

The process of obtaining a Beijing hukou is like an exam, where all the advantages that each person who wants to settle in Beijing has been quantified into points. For example, one point can be earned for owning a property in Beijing, and three points can be earned for paying the provident fund and taxes every year. [7]. It is the most difficult for individuals and business owners to settle in Beijing, as individuals need to have a master's degree or above and win awards such as the "China Patent Gold Award." At the same time, business owners also need to meet many requirements. The "Trial Measures" stipulate that applicants applying for permanent residence in some districts like Dongcheng should be the person in charge of the private enterprise for three consecutive years or the legal representative of other forms of private enterprises. Own their home in the place where the hukou moved; pay taxes of more than RMB 800,000 per year for three consecutive years or pay taxes of 3 million yuan in the last three years. The enterprise has paid taxes of at least RMB 800,000 per year for three consecutive years or at least RMB 3 million in the last three years. The number of employees in the city has remained at least 100 or at least $90 \%$ of the total employees for three consecutive years. How high is the threshold for a Beijing household registration?[8]

Many agents post hukou for sale on search engines and social platforms. Since it is too difficult to get a Beijing hukou through normal channels, "how to get a Beijing hukou" has become a mature underground black industry chain, which involves buying a Beijing hukou through the underground hukou market. The main reason is that there are ways to secure a job with a state-owned enterprise, a central enterprise, or an international organization in Beijing and to get a Beijing hukou book and ID card. The price is about four hundred and fifty thousand RMB.[9]1 Therefore, marrying someone who owns a Beijing hukou becomes a quick and legal way to live in Beijing permanently.

\section{IN THE DATING MARKET}

Besides being difficult to obtain, what are the other features of the Beijing hukou that can establish its place in the dating market? Employment is an important reason. Beijing is the political centre of China. From the perspective of employment, Beijing has 76 central enterprises. This has indirectly led to Beijing's ranking first in the country regarding employment quality. [10] The state investment weight ratio accounts for forty-three per cent, which is significantly ahead of other cities in China. According to the older generation, it is a great honour for children to enter state-owned enterprises with decent work, stability, and good benefits. Due to the influence of their parents, many college students strive to work in state-owned enterprises after graduation. With such many central and state-owned enterprises in Beijing, it is naturally ideal for children who grew up with the older generation's views to obtain a Beijing hukou, which allows them to contact many state-owned enterprises.

Beijing has the largest number of central state-owned enterprises, far more than any other city. [11] Working at headquarters has a higher platform and more access to superiors, which will undoubtedly help them in the future. For example, after a few years of working, they are more likely to get promoted when they transfer to some local units. 


\subsection{For houses}

Responding to the considerable attraction of the Beijing hukou for Chinese women in the marriage market, our group analyses the phenomenon from the following aspects. One of the advantages of having a Beijing residence is that it gives people preferential treatment and benefits in purchasing houses. In contrast, the home purchase incentives that people from outside the province have will be much lower than those who own a Beijing hukou.[12] What is more, the Beijing hukou allows married families to purchase up to 2 houses.[12] More property resources mean many choices. The issue of school district housing has always been a hot topic of discussion due to the school district system. Those with a Beijing household registration undoubtedly have more options for selecting educational resources for their offspring. Due to the quest for good learning resources, school district housing prices continue to rise.

For example, a small house in Wenchang Hutong near Beijing Experimental Primary School No. 2, with a unit size of only 10 square meters, is priced at RMB 3.4 million, translating into 340,000 yuan per square meter.[13] Recently, China Economic Weekly, the China Institute of Economic Research, and Chain Home Real Estate launched the "Beijing School District Property Price Map." The map was compiled by selecting a total of 30 critical primary schools in six districts in inner Beijing and selecting representative second-hand properties near these 30 primary schools, using their sales prices in May as a sample. The highest selling price is in the Southeast neighbourhood in Haidian District, a Zhongguancun Primary School district in Haidian District, with 89,500 yuan per square meter. The lowest-priced is the Yong Shan Li subdivision in Fengtai District, the school district house of Fengtai Fifth Primary School, and is currently selling for only 33,200 yuan per square meter. According to Chain Home Real Estate's calculations, the current average sales price of these 30 properties is 60,700 yuan per square meter.[13] What can be drawn from above is that the school district housing has significantly impacted Beijing's housing.

\subsection{For education}

A Beijing hukou can provide more educational resources and opportunities for school-age children. Therefore, household transfer agencies will advertise to attract more female participants. They would advertise it as follows: "You can spend less money to access upscale places of learning, and having a Beijing hukou gives you a huge advantage for college entrance exams. Students do not have to pay school fees for compulsory education and high school, and they do not have to run out of time to get a permit. They have a greater chance of going to Tsinghua University or Beijing University simultaneously. " [14]

Among the higher education institutions in China, the most prestigious and recognized universities are called "985 universities" or "211" universities, even though they were cancelled in 2016. The 985 Project referred to that on May 8th, 1998, Chinese leaders announced the support of a group of world-class universities. The 211 Project meant one hundred top universities in the 21 st century, including all the universities supported by the 985 Project. 985 and 211 had also become synonymous with China's top higher education institutions.[15] Beijing is home to some of the best educational resources in China, including 8 of 985 universities, led by Tsinghua University, and 26 of 211 universities. According to the data, the total number of public colleges and universities run by the central government in China is 118, of which Beijing has 39 . There are 13 adult colleges and universities run by the central government, of which Beijing has 8.[16]

What is more, according to the seventh census, there were $218,360,767$ people with university education, $213,005,258$ people with high school education, $48,716,3489$ people with junior high school education, and $34,965,828$ people with primary school education. In every million people, the average number of people with university education is 15467 while this number in Beijing is 41980 . The average number of people with high school education is 15088 , while the number in Beijing is 17593. The average number of people with middle school education is 34507 , while the number in Beijing is 23289. Moreover, the average number of people with primary school education is 24767 , while this number in Beijing is 10503.[17] Another figure shows that in terms of the distribution of "double first-class" universities, Beijing's number of "double first-class" universities is the highest, followed by Jiangsu and Zhejiang, with more than ten universities. [18] From all the data listed above, Beijing leads the country in a higher level of education (meaning upper secondary and above).

\subsection{For transportation}

The Beijing hukou also offers great convenience in terms of transportation. Due to the inadequacy and inconvenience of Beijing's public transport system, more people from Beijing are choosing to travel by private car, which has led to a significant increase in the number of private cars in Beijing. In Beijing, private car licenses are not available for purchase at will but require a lottery waiting list. Only those who own a Beijing hukou, or have legal permanent residence status in Beijing, are eligible to wait in the lottery.[19] 


\section{MATE PREFERENCE OF THE ONLY DAUGHTERS}

Because of the one-child policy, there are many more marriageable men than women in mainland China now. The population of unmarried men has increased significantly than ever before.[20]\[21] The high sex ratio has led to this female generation having a dominant position in the marriage market, with more choices.[22] The only daughters, who changed the conventional status of females in mainland China, have more access to get an education and inherit property. [23]1 They can get a high salary with their outstanding abilities, instead of just being a wife to take care of her family. However, even though they do not have an excellent desire for financial resources, a man with good socioeconomic status would be the first choice in this giant marriage market.

The only daughter, a single girl without any siblings, can easily be a family centre. Instead of their thoughts, their parents chose to give birth to only one daughter due to the policy. They had to give this kid all the love and care, which means she would grow up full of parents' attention, causing psychological immaturity compared with the same aged non-only-daughter. The first time to get in touch with society could be going to the university in many cases. These only daughters have to live alone without their parents' help to face all kinds of difficulties, making them feel a considerable lack of security. In this case, people need to find a person to give them incredible security. [3] Mate preferences and Chinese traditional culture would make sense.

\subsection{Mate preferences}

According to David M. Buss [1], physical attractiveness is essential for males. In contrast, females value getting resources and socio status, supporting their partner to live and feed their children. In general, males hold more resources than women, and to be alive has always been the most crucial thing. No matter where society we are, females value more good financial capacity, bringing a higher quality of life for their future children and themselves. This kind of man instinctively can bring a great sense of security to the only daughters due to evolutionary psychology. In human reproduction, women pay much more in childbirth and care physiologically. As long as men show their financial capacity, they can attract women to impart and inherit their genes.[3] High-income women will pay more attention to their partners' financial capacity.[1]

Only daughters value it more in central Chinese traditional culture discourse. In most cases, exchanging political and financial interests is the key to marriage instead of personal love expectation. [22] When these females go into the marriage market, her whole family, including parents, grandparents, aunts, and uncles, would pay attention to it, even join in. Females have more choices because of the high sex ratio, and her family would love to help her find a man who satisfies all people.

\subsection{Chinese traditional culture}

Filial piety connected with financial capacity could help only daughters to reduce the pressure of providing for the aged. Unlike the western world, where the bond between people comes from faith, instead of blood, due to the widespread of Christianity, filial piety is one of the most basic traditional moral norms in mainland China. [24] The one-child policy gave rise to the uniqueness of children who have to work and support the elder, especially females who play two roles of daughter and daughter-in-law. The central discourse of filial piety requires females to support the elder, even though they have sons. The only daughter suffers from stress from two families, not only the financial resources but also the mental and life support. Although only daughters have more disposable income than ever before, they can afford more pressure when their spouses are only sons.[23] If they choose a man with high socioeconomic status, they do not have to pay as much as before, and a nanny or older people's home could be a good option, which makes couples have more private spaces for themselves.

Other people's comments have a tremendous influence on only daughters' decisions.[22] When a woman goes into the marriage market, people say she should find someone more equal, similar or high socioeconomic status, or a suitable match. Once a male has a lower social position than a female, people would judge that he is unworthy of her, which even causes divorce. Only daughters prefer an excellent match to avoid this, reaching a generally accepted standard. Therefore, a man who can provide better financial resources has become the rage of the marriage market. Moreover, only daughters, who have their property and income, have been forced to choose a better man.

What this part mentioned about males' financial capacity could be supported by Beijing Hukou. Having access to good education can feed children better Houses and cars can make a good quality of life and give people an excellent impression to avoid the worst judgment; a high salary in Beijing can build an excellent socioeconomic status easier than in other cities. Of course, the international working condition can provide more opportunities, which has met only daughters' needs who are ambitious about working.

\section{CONCLUSION}

The beneficial resources of Beijing Hukou, like houses, education and transportation, shaped the higher status of men from Beijing in the dating market and also 
constructed Chinese female mate preference. However, the nature of the pursuit of Beijing Hukou is the pursuit of socioeconomic status resulting from patriarchy. This paper analyses female mate preference under particular Chinese gender circumstances and how only daughters treat Beijing Hukou. The typical only daughters have more resources than non-only daughters while suffering more from all kinds of fields, shaping their mate preference - they will pay more attention to their partners' financial capacity. This paper points to further research about the Hukou system, mate preference, and the one-child policy effects.

\section{REFERENCES}

[1]. David M. Buss (1989) "Sex differences in human mate preferences: Evolutionary hypotheses tested in 37 cultures" BEHAVIORAL AND BRAIN SCIENCES (12), 1-49

[2]. Fu, Q., \& Ren, Q. (2010). "Educational Inequality under China's Rural-Urban Divide: The Hukou System and Return to Education." Environment and Planning. A, 42(3), 592-610.

[3]. Tian, Q. (2012) "A Study of Chinese Women's Tendency to Choose a Mate: An Explanation Based on Evolutionary Psychology." Social Development and Public Policy, vol. 10246, pp. 1-139.

[4]. "Beijing Temporary Regulations on Hukou Management." Ministry of Public Security of China, 1951, http://www.lscps.gov.cn/html/20940.

[5]. "Beijing Population". 2021. National Data. https://data.stats.gov.cn/search.htm? $=0 \mathrm{E} 5 \% 8 \mathrm{C} \% 9$ $7 \%$ E4\%BA $\%$ AC $\%$ E4\%BA\%BA\%E5\%8F\%A3.

[6]. Afridi, F., Li, S., \& Ren, Y. (2015). "Social identity and inequality: The impact of China's hukou system." Journal of Public Economics, 123, 17-29.

[7]. "Beijing's Policy On Household Integration Was Introduced, While Meeting Four Conditions Can Apply.". 2021. City Residence 1994-2021 (C): 92. http://www.cnki.net.

[8]. Cai, F. (2001). "A Tale of Two Cities: Hukou' gold content' and the Hukou reform system." Experts discuss household registration reform.Chinese Academy of Social Sciences. pp. 15.

[9]. Xie, P. \& Shi, E., (2014) "Social Record, Black, and White Way of Beijing Hukou." Township Enterprise Newspaper. (1), 3.

[10].Dong, L., Ma, L. (2015) "Escape or go to Beijing? The policy of settling in Beijing for high school graduates and employment options for graduates." Economy and Education. 10087, (3) 15.

[11].State-owned Assets Supervision and
Administration Commission of the State Council. (2021) List of central state-owned enterprises. http://www.sasac.gov.cn/n2588035/n2641579/n264 1645/index.html.

[12]."Beijing Home Buying Guide". 2016. Beijing Municipal Commisson of Housing and Urban-Rural Development. http://zjw.beijing.gov.cn/bjjs/xxgk/ztzl/bjgfzn/gfzgs q/index.shtml.

[13].Liu, D. (2014). "Beijing's 'school district houses' are going crazy." China Economic Weekly. pp. $2-28$.

[14]."Beijing Settlement Solutions". 2021. Aonuojinhang. http://settlebj.aonuojinhang.com/.

[15]."985" And "211" Legal Thinking About The Classification Of Higher Education Institutions". 2012. JOURNAL OF HUAIHUA UNIVERSITY 34. (2) (Feb. 2015): 114-120. doi:10.16074/j.cnki.cn43-1394/z.2015.02.026.

[16]."Table of the number of higher education schools." (2020). Ministry of Education of the People's Republic of China.http://www.moe.gov.cn/s78/A03/moe_560/jy tjsj_2019/gd/202006/t20200611_464854.html.

[17]."Table of the number of graduate students in scientific research institutions." (2021). Ministry of Education of the People's Republic of China.

[18].Du, P. (2021). "Analysis of the Fairness of Higher Education Resource Allocation in China: Based on the Thayer index and the Gini coefficient." Science Education Article Summary. The Science Education Article Collects. 531, (15) 9-13.

[19].Jining, Chen. 2020. "Beijing Provisional Regulations On The Regulation And Control Of The Number Of Small Buses.". Window of Beijing. http://www.beijing.gov.cn/zhengce/zhengcefagui/2 02012/t20201206_2157922.html.

[20].Guo, Zhen, Shuzhuo Li, and Marcus W. Feldman. 2018. "A Study Of Marriage Squeeze Patterns Among Chinese Men". China Population Science 2016 (3): 69-127. doi:14CRK025.

[21].Li L., M.D., \&Zhu, W.X. (2008). "The Effect of China's One-Child Family Policy after 25 Years." The new england journal of medicine. health policy reports. pp. 1171-1176.

[22].Chen, X (2018) "Choosing the best to marry: the social basis and influence of contemporary Chinese women's marriage choice" Contemporary Youth Research No.354 No.3 pp.78-83

[23].Wang, Q. (2016). "Analysis on the pension 
dilemma and Countermeasures of one-child families" Journal of Anyang Institute of Technology Sept. Vol.15 No.5 pp. 36-37

[24].Liu, Y. (2006). "A preliminary comparison of Chinese and Western retirement culture." Southwest University of Finance and Economics. pp. $1-60$ 